\title{
Use of Synthetic Data to Test Flight Patterns for a Boundary Layer Field Experiment
}

\author{
Edi SANTOSo AND Roland Stull \\ Atmospheric Science Programme, Department of Geography, University of British Columbia, Vancouver, \\ British Columbia, Canada
}

(Manuscript received 13 July 1998, in final form 28 October 1998)

\begin{abstract}
A virtual research aircraft was flown through a synthetic atmospheric boundary layer to help design a real flight plan that would allow robust turbulence statistics to be obtained in a heterogeneous, evolving, convective boundary layer. The synthetic boundary layer data consisted of a field of coherent, large-diameter, thermal updraft/downdraft structures, superimposed in random smaller-scale turbulence having a Gaussian distribution. These large and small eddy perturbations, with scales set from published empirical relationships, were superimposed on the expected mean profiles of wind and potential temperature. The goal was to determine whether sufficiently robust line-averaged statistics could be gathered to study a new similarity theory for the radix layer, the bottom fifth of the convective boundary layer, where mean profiles are not uniform with height.

After testing a variety of flight patterns with the synthetic data, a vertical zigzag pattern of slant ascent/descent legs was selected as the best compromise, given typical aircraft flight and safety constraints. This flight pattern was then successfully flown with the University of Wyoming King Air aircraft in the real atmosphere during Boundary Layer Experiment 1996 (BLX96) over Oklahoma and Kansas. Postexperiment comparison revealed that the synthetic data exhibited less scatter than the actual data, perhaps caused by a heterogeneous surface and a nonstationary boundary layer. Based on this comparison, some practical recommendations are given for future use of synthetic boundary layer data.
\end{abstract}

\section{Introduction}

Some meteorological instrument systems are so expensive, or their deployment so complex, that it is wise to first test the feasibility of the experimental plan using virtual instruments or synthetic data. This allows problems to be detected and remedied at relatively low cost, before the physical instrument is constructed, launched, or deployed. Also, alternative experimental procedures can be tested and compared to find the optimum procedure.

Synthetic experiments have been used in the past to test new instruments for weather satellites (Atlas et al. 1985; Bell 1987; Hedin 1991; Green 1983; Liou and Ou 1979; Meneghini et al. 1986). The monetary cost and scientific loss of launching an inadequate satellite instrument is so prohibitive that it makes sense to try to simulate instrument performance as much as possible before construction and launch.

The synthetic data approach is a powerful tool that can also be applied to other types of instrument systems and meteorological field experiments, including those

Corresponding author address: Roland Stull, Atmospheric Science Programme, Department of Geography, University of British Columbia, 1984 West Mall, Vancouver, BC V6T 1Z2, Canada. E-mail: rstull@geog.ubc.ca in the boundary layer (BL). For example, we needed in situ observations of wind and temperature profiles having very high vertical and temporal resolution, made in a region of the BL where one must average over a large number of coherent thermal structures to get robust statistics. Given the trade-offs of various instruments that were available for the variety of sites needed, it was concluded that airborne measurements would be the most feasible.

However, with a finite aircraft speed of order $100 \mathrm{~m}$ $\mathrm{s}^{-1}$ and the need for long flight legs of order $70 \mathrm{~km}$ to get robust turbulence statistics, there was concern whether nonstationarity and horizontal heterogeneity in the BL would create mutually exclusive requirements for the flight. Namely, if a horizontal flight leg were long enough to average over sufficient thermals rising from a heterogeneous surface, then would the duration be so long that the BL would change during the flight?

For this reason, we realized that it would be wise to first test alternative flight patterns using synthetic data. We created a synthetic dataset having the same statistical characteristics as a field of large coherent thermal structures superimposed on quasi-random smaller-scale turbulence, all embedded within a BL having typical mean wind and temperature profiles. Then we "flew" a hypothetical aircraft through this synthetic BL, where the aircraft speed and data sampling rate mimicked those 
of the real aircraft. We analyzed the resulting time series of synthetic data as if it were real data, using our existing aircraft data analysis package to find the best fit mean wind and temperature profiles, and corresponding variances and covariances.

We found that the traditional flight pattern of horizontal flight legs stacked at different altitudes was inadequate for our needs because of BL nonstationarity and heterogeneity. We then tested a variety of alternative flight patterns using the synthetic data, finally settling on a vertical zigzag pattern that gave reasonably robust turbulence statistics. Our numerical simulations came to fruition when we later adopted this as one of our flight patterns for the real field experiment flown using the University of Wyoming (UW) King Air aircraft over Kansas and Oklahoma in summer 1996.

The purpose of this paper is to describe how synthetic data can be used to good advantage in planning boundary layer field campaigns, using our particular application as an example. We review in section 2 the BL theory that motivated this work and that set the requirements (section 3) for the synthetic flights. Section 4 describes the procedures we used to construct the synthetic data field, while section 5 describes how we collected the synthetic time series by flying a virtual aircraft for a variety of case studies. Analysis of the resulting time series to yield wind and temperature profiles and statistics is described in section 6 , and comparisons with actual flight data are discussed in section 7.

\section{Radix layer review}

During convective conditions with statically unstable air, one can identify subdomains of the convective mixed layer (ML) having different similarity scalings. Using wind speed as an example, winds are zero near the ground and smoothly increase until finally becoming tangent to the vertically uniform winds in the mid-ML (Santoso and Stull 1998). In this middle layer, called the uniform layer (UL), wind speed and direction are nearly uniform, but subgeostrophic, with height. Above that is the entrainment zone, a transition layer between the subgeostrophic UL below and the nearly geostrophic free atmosphere above. At the bottom of the ML is the surface layer (SL), the nearly constant flux region where Monin-Obukhov (MO) similarity theory applies. In this layer, the wind profile is nearly logarithmic, caused by mechanically generated turbulence within the wall shear flow (Stull 1996).

There is a region or gap between the top of the SL and the bottom of the UL where some researchers feel that SL similarity theories fail. To better explain this portion of the ML, Santoso and Stull (1998) analyzed data from the 1973 Minnesota field experiment (Izumi and Caughey 1979) and were able to define a radix layer $(\mathrm{RxL})$ as the region between the surface and the bottom of the UL that obeys a similarity different than MO. The classic SL is a subdomain within the bottom of the RxL. The Latin word "radix," meaning "origin" or "root," was used to name this layer because it is the root of convective thermals. Within the RxL the wind and temperature profiles are influenced by both SL and ML scales. Typical depths of the RxL are on the order of hundreds of meters for wind profiles and tens of meters for temperature profiles. Not all researchers are yet convinced of the need for a radix layer similarity theory, nor of the suitability of the radix layer to succeed as a framework for such a new similarity theory. One of the motivations for a field experiment was to further explore these issues.

Based on these Minnesota data, the following empirical relations (Santoso 1993; Santoso and Stull 1998) were found to describe the vertical profiles of mean wind speed $\bar{M}$ and potential temperature $\bar{\theta}$ within and above the radix layer:

$$
\begin{aligned}
\bar{M} & = \begin{cases}\bar{M}_{\mathrm{UL}}\left(\frac{z}{z_{r m}}\right)^{A_{1}} \exp \left[A_{1}\left(1-\frac{z}{z_{r m}}\right)\right] & \text { for } z \leq z_{r m} \\
\bar{M}_{\mathrm{UL}} & \text { for } z>z_{r m},\end{cases} \\
\bar{\theta}-\bar{\theta}_{\mathrm{UL}} & = \begin{cases}\left(\bar{\theta}_{0}-\bar{\theta}_{\mathrm{UL}}\right)\left\{1-\left(\frac{z}{z_{r t}}\right)^{A_{2}} \exp \left[A_{2}\left(1-\frac{z}{z_{r t}}\right)\right]\right\} & \text { for } z \leq z_{r t} \\
0 & \text { for } z>z_{r r},\end{cases}
\end{aligned}
$$

where $\bar{M}_{\mathrm{UL}}$ and $\bar{\theta}_{\mathrm{UL}}$ are mean wind speed and potential temperature in the uniform layer; $\bar{\theta}_{0}$ is mean potential temperature at the height of the roughness length for temperature; $z_{r m}$ and $z_{r t}$ are the depths of the RxL for wind and temperature; $z$ is height above the surface; overbars represent a horizontal-average ergodic approximation to the ensemble average; and $A_{1}$ and $A_{2}$ are empirical constants of 0.096 and 0.101 respectively. 


\section{Need for special data}

Field experiment data for the RxL are very limited. As was shown by Santoso and Stull (1998), it is impossible to use SL tower data at low altitudes with rawinsonde data aloft, because there is usually an artificial gap between the two profiles at altitudes where accurate RxL data are needed most. The first system gives good time averages while the second system gives snapshots with large sampling error. This experimental artifact of a discontinuity between the two segments of wind or temperature profiles would give large errors if used to analyze the RxL. A new field experiment with consistent time or space averages at all heights was needed to get better understanding of this region.

Other sensing platforms such as wind profilers or radio acoustic sounding systems were inadequate for this research because of the low-altitude data void associated with receiver-transmitter ringing feedback and other instrument characteristics. One possible source of data would be very tall (200-300 m) instrumented towers, although their measurements would be for a small-footprint quasi-homogeneous plot of land, rather than the average over typical heterogeneous landscapes that we desired. Also, we wanted to investigate whether the RxL profiles depended on surface roughness length, which meant that we needed to make similar measurements over different landscapes.

Based on these factors, we concluded that an instrumented aircraft would be most likely to give us the needed data. As stated in section 1, conventional horizontal flight legs were found to be inadequate. For this reason we proposed using a rarely used pattern, namely, a vertical zigzag. Lenschow et al. (1988a,b) had used it in the nocturnal BL, but to our knowledge it had not been used during daytime convective conditions when there are $1-2-\mathrm{km}$ diameter coherent thermal structures and a full spectrum of turbulence. It was unknown whether such a vertical zigzag would be able to collect sufficiently high vertical resolution profile data of winds and potential temperature with sufficiently robust statistics needed to test the radix profile equations. This was the motivation for the synthetic sampling study reported here.

\section{Synthetic data-generation procedures}

To generate the synthetic turbulence data, we superimpose the effects of three components: 1) background profiles of mean variables, 2) perturbations associated with coherent thermal updrafts and downdrafts, and 3) perturbations from random Gaussian fluctuations representing medium- and small-scale turbulence. For the first component (mean profiles) we used the RxL similarity equations (1) and (2) described in section 2.

For the second component (coherent structures), published empirical formulations of Stull (1990) and Young (1988b) were used for horizontal wind speed $M_{u}^{\prime}$ and potential temperature $\theta_{u}^{\prime}$ perturbations within thermal updrafts:

$$
\begin{aligned}
M_{u}^{\prime}= & u_{*}\left[-1.5+0.5\left(\frac{z}{z_{i}}\right)^{1 / 2}\right] \\
\theta_{u}^{\prime}= & \left\{-0.5\left(1-\frac{0.2}{\left[1-100\left(0.9-\frac{z}{z_{i}}\right)^{2}\right]}\right)+2\left|0.9-\frac{z}{z_{i}}\right|\right\} \\
& \times \frac{\frac{w^{\prime} \theta_{v s}^{\prime}}{w_{*}}}{[3}
\end{aligned}
$$

where $z_{i}$ is ML depth, $u_{*}$ is friction velocity, $w_{*}$ is Deardorff velocity $\left[\left(g / T_{v}\right) z_{i} \bar{w}^{\prime} \theta_{v s}^{\prime}\right]^{1 / 3}, g$ is gravitational acceleration, $T_{v}$ is average absolute virtual temperature, $\overline{w^{\prime} \theta_{v s}^{\prime}}$ is the surface eddy covariance value of kinematic vertical virtual potential temperature flux (a measure of buoyancy flux), and subscript $u$ denotes updraft. During free convection, thermal updrafts usually contain slower horizontal wind and warmer potential temperature than the surrounding air.

In the downdraft environment, wind $M_{d}^{\prime}$ and potential temperature $\theta_{d}^{\prime}$ perturbations are set to counterbalance the updrafts, in order to conserve mass, heat, and momentum:

$$
\begin{gathered}
M_{d}^{\prime}=-\frac{f_{u}}{f_{d}} M_{u}^{\prime}, \\
\theta_{d}^{\prime}=-\frac{f_{u}}{f_{d}} \theta_{u}^{\prime},
\end{gathered}
$$

where $f_{u}$ and $f_{d}$ are fractional cross sections of updraft and downdraft areas, and subscript $d$ denotes downdraft. The minus sign indicates the opposite direction. As reported by Greenhut and Khalsa (1982, 1987), Khalsa and Greenhut (1985, 1987), Godowitch (1986), and Young (1988a,b), we also assumed for some of our case studies that there can be background air that is neither in coherent updrafts or downdrafts. The velocity and potential temperature excesses of this background air are zero.

For the quasi-random third component, we used a random number generator to pick wind and potential temperature perturbations from a Gaussian distribution having standard deviations based on the published empirical results of Panofsky et al. (1977), Caughey and Palmer (1979), and Sorbjan (1986). These standard deviations are

$$
\begin{aligned}
& \sigma_{M}= \begin{cases}u_{*}\left(12-0.5 \frac{z_{i}}{L}\right)^{1 / 3} & \text { for } z \leq 0.1 z_{i} \\
0.6 w_{*} & \text { for } 0.1 z_{i}<z \leq z_{i},\end{cases} \\
& \sigma_{\theta}=1.4\left(\frac{z}{z_{i}}\right)^{-1 / 3}\left(1-1.2 \frac{z}{z_{i}}\right)^{2 / 3} \frac{\frac{w^{\prime} \theta_{s}^{\prime}}{w_{*}}}{w_{*}}
\end{aligned}
$$


where $\sigma_{M}$ and $\sigma_{\theta}$ are wind and potential temperature standard deviations, $L$ is Obukhov length, and $\overline{w^{\prime} \theta_{s}^{\prime}}$ is turbulent kinematic heat flux near the surface.

Combining these three components gives the total synthetic wind and temperature for thermal updrafts:

$$
\begin{aligned}
M_{u} & =\bar{M}+M_{u}^{\prime}+G \sigma_{M} \\
\theta_{u} & =\bar{\theta}+\theta_{u}^{\prime}+G \sigma_{\theta},
\end{aligned}
$$

background air (subscript $b$ ):

$$
\begin{gathered}
M_{b}=\bar{M}+G \sigma_{M} \\
\theta_{b}=\bar{\theta}+G \sigma_{\theta},
\end{gathered}
$$

and environmental downdrafts:

$$
\begin{aligned}
M_{d} & =\bar{M}+M_{d}^{\prime}+G \sigma_{M} \\
\theta_{d} & =\bar{\theta}+\theta_{d}^{\prime}+G \sigma_{\theta},
\end{aligned}
$$

where $G$ is a dimensionless random number with Gaussian distribution of unit standard deviation (Press et al. 1992).

All of the equations (9)-(11) are functions of height. There is no need, however, to use these equations to create a full 2D or 3D field of turbulent ML quantities through which we fly the virtual aircraft. The reason is that we need the synthetic data at only those locations where the virtual aircraft will fly. Thus, our approach is to first define the track of the virtual aircraft through 2D or 3D space, and then solve (9)-(11) "on the fly", at the virtual aircraft locations, to create a synthetic time series of sampled data as would be measured at the aircraft. This process is described in more detail in sections 5 and 6 , and is efficient in computational time and memory requirements.

When flying a virtual aircraft through this synthetic data, it is assumed that a sequences of data points will be in an updraft, the next sequence will be in background air if any exists, and the next sequence will be in downdraft air. The duration of each sequence is set to correspond to typical updraft and downdraft diameters, which are reported in the literature to be proportional to the ML depth. A full flight track would include many such sequences. Based on conditional sampling of aircraft data, Greenhut and Khalsa (1982, 1987), Khalsa and Greenhut (1985, 1987), Godowitch (1986), and Young (1988a,b) suggest that well-defined thermal updrafts cover $15 \%-43 \%$ of horizontal area, while welldefined downdrafts cover about 20\%-55\%. The remaining percentage is categorized as background air. The next section describes how time series of synthetic data are created by flying virtual aircraft through the boundary layer just defined.

\section{Synthetic data case study definition}

To synthesize data using the previous equations, we must specify information such as convective BL depth $z_{i}$, RxL depths $z_{r m}$ and $z_{r t}$, turbulent kinematic heat flux at the surface $\overline{w^{\prime} \theta_{s}^{\prime}}$, friction velocity $u_{*}$, Deardorff velocity $w_{*}$, average wind speed and potential temperature in the uniform layer $M_{\mathrm{UL}}$ and $\theta_{\mathrm{UL}}$, potential temperature at (near) the surface $\theta_{0}$, and Obukhov length $L$. The vertical zigzag flight pattern is designed to span the SL, the RxL, and the bottom of UL. For typical ML depths of about $1 \mathrm{~km}$, we thus want to generate vertical profiles of mean wind and potential temperature between altitudes of about 10 and $600 \mathrm{~m}$ above ground level (AGL). One of the goals of our synthetic experiments is to test a variety of zigzag options, such as the number of ascent/ descent pairs (A/D).

In this study we consider two cases of horizontal distribution of thermals: one where thermals are evenly distributed, and the other for random distributions. In the real atmosphere, thermals have been observed to have quasiperiodic spacing, such as across horizontal roll vortices. Our simulations with both regularly spaced and random locations are designed to give us information that brackets the characteristics of the real atmosphere, thereby allowing us to determine optimum flight distances for worse-case thermal spacings.

In the evenly distributed case, thermals are assumed to have uniform cross-section diameter of order $z_{i}$, and any two neighboring thermals are separated by downdrafts (and in some experiments by both downdrafts and background air) that are also evenly distributed. For example, for a case where the thermals cover one-third of the flight path and downdrafts cover two-thirds of the flight path, this means that the synthetic aircraft will pass through a sequence of pairs of 1-km cross-section thermal updraft and 2-km downdraft. For these evenly spaced cases, the virtual flights are designed to pass through the middle of all the thermals.

For the randomly distributed cases, thermal positions and diameters are chosen randomly. The diameter is distributed normally about a mean value of $z_{i}$, with the Gaussian tails cut off at $0.1 z_{i}$ and $1.9 z_{i}$. The two nearest thermals are separated by downdrafts that are set to be no less than 1.1 times the average of their diameters. Although as reported here we used a Gaussian distribution of thermal characteristics for our synthetic work prior to the actual field experiment in 1996, we realize now that a lognormal distribution might have been more appropriate. Lognormal distributions are also easy to create in synthetic data, and we recommend that other researchers consider using such distributions if they create their own synthetic datasets for the mixed layer.

For simplicity in this study we will assume that the surface is flat, and the virtual flights are always crosswind. We use a horizontal aircraft speed component of $100 \mathrm{~m} \mathrm{~s}^{-1}$ regardless of ascent or descent, a vertical speed of $5 \mathrm{~m} \mathrm{~s}^{-1}$ during the $\mathrm{A} / \mathrm{D}$, and a data sampling rate of $50 \mathrm{~Hz}$, which are typical for the UW King Air aircraft that was to be used later in real life. It is also assumed that the lowest safe altitude is $10 \mathrm{~m}$, while the highest altitude is dependent on the horizontal distance 
TABLE 1. Meteorological sets used for evenly distributed synthetic thermals (see text for notation).

\begin{tabular}{ccccccccc}
\hline \hline $\begin{array}{c}\text { Set } \\
\text { index }\end{array}$ & $\begin{array}{c}z_{i} \\
(\mathrm{~m})\end{array}$ & $\begin{array}{c}z_{r m} \\
(\mathrm{~m})\end{array}$ & $\begin{array}{c}z_{r t} \\
(\mathrm{~m})\end{array}$ & $\begin{array}{c}\overline{w^{\prime} \theta_{s}^{\prime}} \\
\left(\mathrm{K} \mathrm{m} \mathrm{s}^{-1}\right)\end{array}$ & $\begin{array}{c}u_{*} \\
\left(\mathrm{~m} \mathrm{~s}^{-1}\right)\end{array}$ & $\begin{array}{c}w_{*} \\
\left(\mathrm{~m} \mathrm{~s}^{-1}\right)\end{array}$ & $\begin{array}{c}M_{\mathrm{UL}} \\
\left(\mathrm{m} \mathrm{s}^{-1}\right)\end{array}$ & $\begin{array}{c}\theta_{\mathrm{UL}} \\
(\mathrm{K})\end{array}$ \\
\hline A & 2000 & 185 & 32 & 0.20 & 0.25 & 2.35 & 7.5 & 292.5 \\
B & 1000 & 130 & 25 & 0.10 & 0.25 & 1.50 & 6.0 & 285.5 \\
$(\mathrm{~K})$
\end{tabular}

covered by each A/D pair, using an aircraft vertical velocity that is constant for all virtual flights.

To capture some of the variability of the real atmosphere, we ran simulated flights for various combinations of meteorology and thermal distributions. The meteorological options are identified below as "sets," and the thermal distributions as "cases." Results will be identified by their set and case indices.

\section{a. Evenly distributed thermal cases}

For each of the BL meteorology sets listed in Table 1 , we collect synthetic flight data for the evenly distributed thermal cases of Table 2. Included are trials where the convective BL consists of thermal updrafts and downdrafts only, and other trials with updrafts and downdrafts embedded within background environment air. For some cases the thermal updrafts occupy onethird, one-quarter, or one-fifth of the flight paths, and the rest is occupied by downdrafts. For the other cases, thermals fill one-third, one-quarter, or one-fifth of flight paths, downdrafts occupy one-half, and the rest is background air.

Based on the thermal/downdraft geometry, one can calculate the minimum-required horizontal flight distance per $\mathrm{A} / \mathrm{D}$, total number of $\mathrm{A} / \mathrm{Ds}$ per horizontal track, and total flight path distance needed to get at least two samples in thermals at any point in the vertical domain. For example, in case 1 where one-third of the flight path is covered by thermals and the remainder covered by downdraft, one would need a total horizontal flight distance of $60 \mathrm{~km}$ consisting of three A/Ds of 20$\mathrm{km}$ horizontal distance each in order to get two or more data samples in each 2-m vertical increment. Vertical distance is simply calculated using ratio of vertical to horizontal speeds of the aircraft, multiplied by horizontal distance. Therefore, for case 1 the vertical distance is $500 \mathrm{~m}$ above the lowest height $(10 \mathrm{~m})$, giving a max- imum altitude of $510 \mathrm{~m} \mathrm{AGL}$ at the top of the A/D pattern.

For those cases that include ambient background air in addition to thermal updrafts and downdrafts, although the downdraft and background air vary, they neither influence the total flight distance nor the total A/D patterns individually, because total flight distance is determined by relative comparison of the percentage of the thermals and of the percentage of the remainder. For example, in case 2, the total fight distance needed also happens to be $60 \mathrm{~km}$, which consists of three up-down patterns of $20-\mathrm{km}$ horizontal distance each, with a maximum altitude of $510 \mathrm{~m}$ AGL. Total horizontal distances listed in Table 2 are only minimum distances required for uniformly distributed thermals. For variable diameters, one would need longer total horizontal flight distances than those listed in Table 2.

Simulating the six flight path/thermal cases of Table 2 for each of the two sets of BL meteorology of Table 1 yields 12 trials that were performed. Figures 1-3 show only a subset of these, to save space. The outcome regarding optimal experimental design is discussed in a later section.

\section{b. Randomly distributed thermals}

To more faithfully represent the range of meteorological conditions expected over Kansas-Oklahoma where the real Boundary Layer Experiment 1996 (BLX96) field program was to take place, three additional sets of synthetic meteorological data were created, listed in Table 3.

The creating of randomly distributed synthetic thermals is a bit more complicated than for the even distribution. Here, we consider a $100 \mathrm{~km} \times 100 \mathrm{~km}$ horizontal domain, within which thermal diameters and positions are distributed randomly. The distance between the centers of any two neighboring thermals is set to be

TABLE 2. Thermal distribution cases for evenly distributed thermals. A/D represents one ascent/descent pair of flight legs.

\begin{tabular}{|c|c|c|c|c|c|c|c|}
\hline \multirow{2}{*}{$\begin{array}{l}\text { Case } \\
\text { index }\end{array}$} & \multicolumn{3}{|c|}{ Fraction of area covered by } & \multirow{2}{*}{$\begin{array}{l}\text { Horizontal } \\
\text { distance per } \\
\mathrm{A} / \mathrm{D}(\mathrm{km})\end{array}$} & \multirow{2}{*}{$\begin{array}{l}\text { Total number } \\
\text { of A/Ds }\end{array}$} & \multirow{2}{*}{$\begin{array}{c}\text { Total } \\
\text { horizontal } \\
\text { dist. }(\mathrm{km})\end{array}$} & \multirow{2}{*}{$\begin{array}{c}\text { Vertical } \\
\text { distance }(\mathrm{m}) \\
(\text { above } 10 \mathrm{~m})\end{array}$} \\
\hline & updraft & downdraft & background & & & & \\
\hline 01 & $1 / 3$ & $2 / 3$ & 0 & 20 & 3 & 60 & 500 \\
\hline 02 & $1 / 3$ & $1 / 2$ & $1 / 6$ & 20 & 3 & 60 & 500 \\
\hline 03 & $1 / 4$ & $3 / 4$ & 0 & 22 & 4 & 88 & 550 \\
\hline 04 & $1 / 4$ & $1 / 2$ & $1 / 4$ & 22 & 4 & 88 & 550 \\
\hline 05 & $1 / 5$ & $4 / 5$ & 0 & 24 & 5 & 120 & 600 \\
\hline 06 & $1 / 5$ & $1 / 2$ & $3 / 10$ & 24 & 5 & 120 & 600 \\
\hline
\end{tabular}



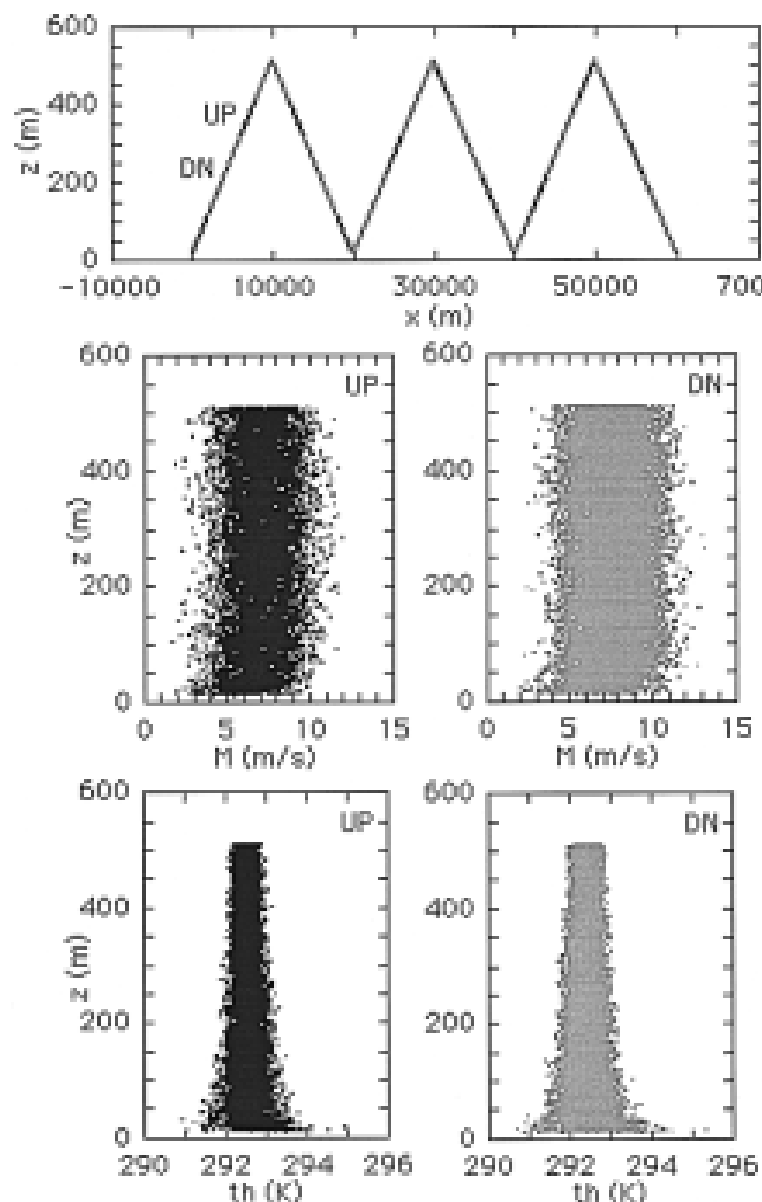

FIG. 1. Top: Vertical zigzag flight pattern for synthetic data trial A01, for which thermals are evenly distributed. Dark lines indicate the portion of the flight track in updrafts, while medium gray lines indicate downdrafts. Middle left: Wind speed (M) raw synthetic data points obtained during the virtual zigzag flight, conditional sampled to include only the updraft data (UP). Middle right: Same, but for downdrafts (DN). Bottom: same as middle but for potential temperature (th). The total number of synthetic data points is 30000 .

greater than 1.1 of the average of their diameters. In creating randomly distributed thermals we assume that, on average, the thermals cover one-third of the area. Within the $100 \mathrm{~km} \times 100 \mathrm{~km}$ domain, we randomly pick five points as starting locations for five flight tracks. Thus, for any one realization (i.e., flight track) it is possible that the line-averaged thermal coverage will be less or greater than the one-third overall area average, as shown in Table 4. Table 4 also lists the coordinates of the starting points of each virtual flight track.

Because the distribution is random, we realized that flight distances needed to be longer than for the evenly distributed cases, in order to get robust statistics. Our choice of synthetic flight distance is $72 \mathrm{~km}$ ( $20 \%$ longer than for the evenly distributed thermals), consisting of three A/D patterns of $24 \mathrm{~km}$ each. Horizontal and vertical speeds of the aircraft are the same as those for evenly distributed cases, as is the lowest altitude the aircraft could reach. Again, of the 15 trial simulations that were performed, only a few are plotted here (Figs. 4-6) for illustration.

\section{Mean wind and potential temperature vertical profiles}

An example of the time series of synthetic data is plotted in Fig. 7. Such synthetic data are used here as input to our data analysis packages as if it were from a real aircraft, both to test the adequacy of our analysis algorithms and to confirm whether the number of A/D pairs is optimal for the BLX96 field program.

First, the data are sorted by altitude into nonoverlapping bins of 2-m vertical depth. Because several slant A/D legs were flown, each bin will contain data points from different horizontal locations along the flight path. The average of each bin is assigned to a height at the bin center.

The resulting bin averages plotted in Figs. 8 and 9 (only some are shown here to save space) still have scatter associated with sampling error. The reason is that, by chance, some bins might have sampled more updrafts than downdrafts, while other bins might have sampled different portions of the two or three idealized air types (up, down, background).

Next, as if this were real data, nonlinear regression is used to fit (1) and (2) to the profile data. These bestfit curves are plotted in Figs. 8 and 9, as solid lines (again only some are shown here). The input mean profiles that were used to generate the synthetic data are not plotted here because they virtually coincide with the best fit results. Tables 5 and 6 compare the RxL parameters that were input to those found from analyzing the synthetic data. If our synthetic data were sufficiently realistic, then the difference between the analyzed and input parameters is a measure of the expected difference between aircraft-measured and true atmospheric parameters. Namely, it is one measure of expected experimental error, which includes the effects of sampling error by the aircraft and analysis error by our analysis algorithms. In a real field experiment the number of slant A/D legs is constrained by nonstationarity of the BL, and mesoscale heterogeneity, as previously discussed.

Based on these competing factors, and utilizing what we learned from the synthetic data, our proposed design for the flight pattern of the real aircraft was to have three A/D pairs while flying in one direction over a 72$\mathrm{km}$ horizontal ground track. As will be mentioned later, we had to modify this flight design during the real field experiment because of limitations of the instruments and data system on the King Air aircraft. A comparison with the actual flight results is given in the next section.

For the evenly distributed cases (see examples in Fig. 8 ), the synthetic wind data were more scattered than was temperature. Nevertheless, the synthetic data of mean wind and potential temperature were distributed around the input mean profiles (not plotted in Fig. 8) 

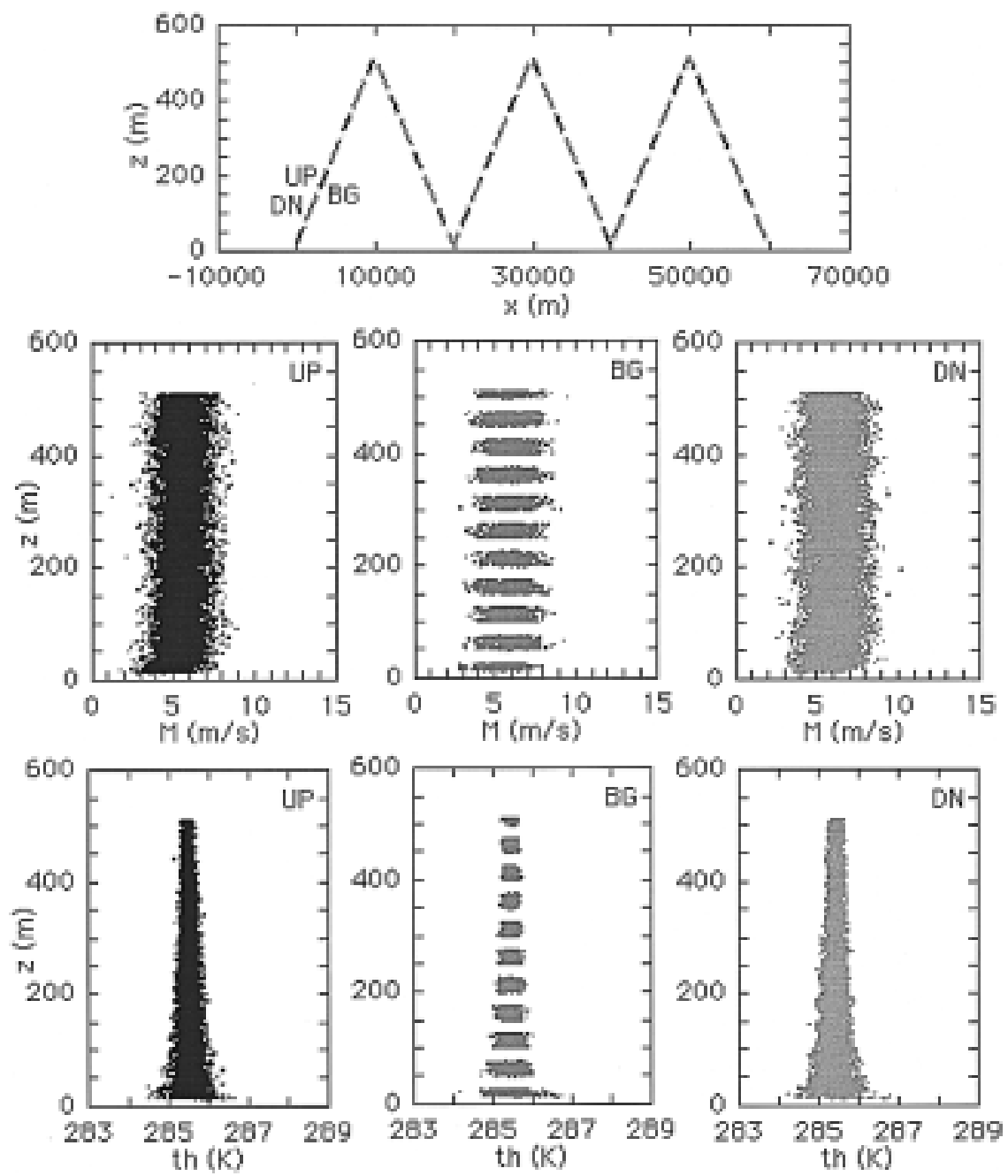

FIG. 2. Same as Fig. 1, but for trial B02. Light gray indicates background (BG) data points that are in neither up- nor downdrafts. In the top figure the very light gray (or white in some printings) portions of the vertical zigzag indicate background (BG) data points that are neither updrafts nor downdrafts. The data collected along these portions of the flights are printed in medium gray in the bottom center two figures labeled BG.

and represented them very well. It can be seen in Table 5 that $z_{r m}, z_{r t}, M_{\mathrm{UL}}, \theta_{\mathrm{UL}}$, and $\theta_{0}$ found from the best fit are close to their input values. For the evenly distributed cases, the sampled data captured the thermals and downdrafts (and background air) very well for the whole vertical and horizontal domain. The thermals were counterbalanced precisely by the downdrafts (and background air). Theoretically the conservation of mass, heat, and momentum was satisfied not only in the whole vertical and horizontal domains, but also in almost every vertical bin.

For the randomly distributed cases (see examples in Fig. 9), the mean wind and temperature data were more scattered. The data were still distributed around the input mean profiles (not plotted in Fig. 9) quite well, but not as well as for the evenly distributed cases. This could be explained as follows. Though in the whole vertical and horizontal domain, the conservation of mass, heat, and momentum was satisfied, such conservation was not always true in every bin. For randomly distributed thermals, it is likely that in most bins the sampled data representing thermals and downdrafts were not counterbalanced. Those were shown in Fig. 9 for both wind and potential temperature, where the vertical plots were quite wiggly. This amount of scatter was anticipated to be more representative of the real BL.

\section{Comparison with actual flight data}

\section{a. Field site characteristics}

During 15 July-13 August 1996 the University of British Columbia conducted Boundary Layer Experiment 1996 over Oklahoma and Kansas (Stull et al. 

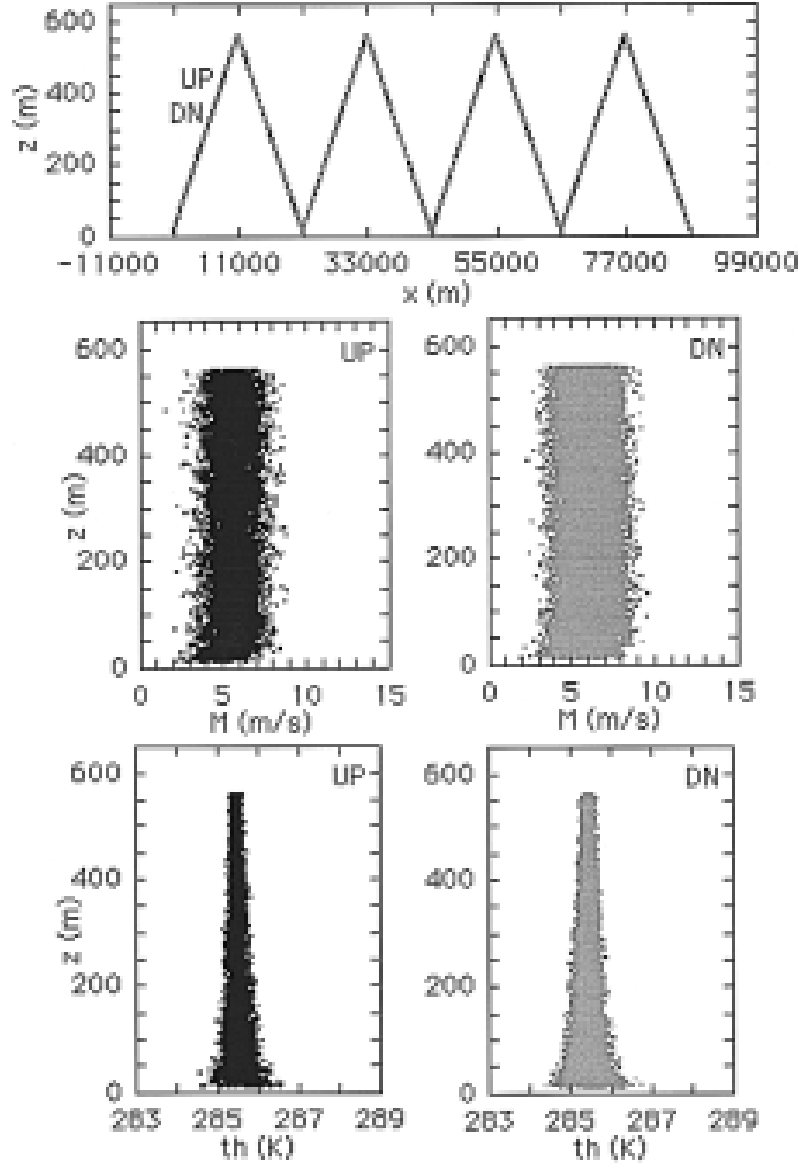

FIG. 3. Same as Fig. 1, but for trial B03. The total number of synthetic data points is 44000 .

1997). The topography gently sloped up toward the west-northwest, with a mean gradient of 1/900. Land use was heterogeneous, and the land varied from mostly flat to some very small, rolling hills. Mean winds were generally from the south, so we flew crosswind flight tracks that were oriented roughly east-west. These King Air aircraft tracks were flown over three different sites having different land use and roughness. These sites were named after nearby villages: Lamont, Winfield, and Meeker.

The Lamont track, in Oklahoma, was primarily over crop land. Terrain under the track was quite flat but gently rising to the west, with elevations ranging from 320 to $425 \mathrm{~m}$. Land use consisted of $60 \%-80 \%$ wheat fields, $40 \%-20 \%$ pasture, and a small number of trees less than $10 \mathrm{~m}$ tall. About $40 \%$ of the cultivated fields were recently plowed at the time of the experiment, leaving the reddish-brown soil bare under portions of the track. The average aerodynamic roughness based on averaged direct calculations and the table classifications (Smedman-Högström and Högström 1978; Stull 1988; Wieringa 1980,1986$)$ was $z_{0}=0.1 \mathrm{~m}$.

The Winfield track, in Kansas, was over predominantly pasture land, but with a small quarry near the middle of the track. Small hills near the center of the track ranged from 70 to $100 \mathrm{~m}$ above local ground level. Terrain was rising to the west, with elevations ranging from 250 to $400 \mathrm{~m}$. Land use consisted of 30\%-60\% pasture, $50 \%-10 \%$ forested areas mostly at the west side of the track, with trees less than $10 \mathrm{~m}$ tall, and the rest was cultivated. The average aerodynamic roughness was $z_{0}=0.9 \mathrm{~m}$.

The Meeker track, in Oklahoma, had greater forest coverage. It had more small rolling hills ranging from 40 to $60 \mathrm{~m}$ above local ground level. Terrain was rising to the west, with elevations from 250 to $280 \mathrm{~m}$. Land use consisted of $40 \%-50 \%$ pasture, $60 \%-40 \%$ wooded areas with trees less than $10 \mathrm{~m}$ tall, and 10\%-30\% cropland primarily near the west end of the track. A $5 \mathrm{~km}^{2}$ lake was just beyond the east end of the track. The average aerodynamic roughness was $z_{0}=1.4 \mathrm{~m}$.

\section{b. Flight patterns}

To investigate the RxL, the vertical zigzag pattern as designed in the previous section was originally to be flown crosswind over each ground track to get vertical profiles of mean wind and potential temperature between altitudes of about 10 and $700 \mathrm{~m}$ AGL. Based on last-minute recommendations of the UW King Air project manager (G. Gordon 1996, personal communication), aircraft vertical velocity during climbs and descents was reduced by roughly half to $2.54 \mathrm{~m} \mathrm{~s}^{-1}$ in order to improve the accuracy of the turbulence measurements. To accommodate this, only one and a half A/D legs could be flown in one direction along the 72$\mathrm{km}$ horizontal track. In order to get sufficient sampling, we decided to immediately reverse course and fly the remaining one and a half A/D legs. This yielded the three total A/Ds that we had determined were necessary using the synthetic data and remained within the same horizontal domain of $72 \mathrm{~km}$; however, the sacrifice came in total time duration, which was now roughly doubled to complete the flight pattern. This compromise flight

TABLE 3. Meteorological sets for randomly distributed thermals.

\begin{tabular}{ccccccrrrr}
\hline \hline $\begin{array}{c}\text { Set } \\
\text { index }\end{array}$ & $\begin{array}{c}z_{i} \\
(\mathrm{~m})\end{array}$ & $\begin{array}{c}z_{r m} \\
(\mathrm{~m})\end{array}$ & $\begin{array}{c}z_{r t} \\
(\mathrm{~m})\end{array}$ & $\begin{array}{c}\overline{w^{\prime} \theta_{s}^{\prime}} \\
\left(\mathrm{K} \mathrm{m} \mathrm{s}^{-1}\right)\end{array}$ & $\begin{array}{c}u_{*} \\
\left(\mathrm{~m} \mathrm{~s}^{-1}\right)\end{array}$ & $\begin{array}{c}w_{*} \\
\left(\mathrm{~m} \mathrm{~s}^{-1}\right)\end{array}$ & $\begin{array}{c}M_{\mathrm{UL}} \\
\left(\mathrm{m} \mathrm{s}^{-1}\right)\end{array}$ & $\begin{array}{c}\theta_{\mathrm{UL}} \\
(\mathrm{K})\end{array}$ & $\begin{array}{c}\theta_{0} \\
(\mathrm{~K})\end{array}$ \\
\hline $\mathrm{C}$ & 2200 & 200 & 34 & 0.20 & 0.25 & 2.45 & 7.5 & 292.5 \\
$\mathrm{D}$ & 1600 & 245 & 50 & 0.20 & 0.45 & 2.20 & 11.8 & 296.5 \\
$\mathrm{E}$ & 1200 & 150 & 28 & 0.10 & 0.25 & 1.60 & 6.0 & 285.5 \\
\hline
\end{tabular}


TABLE 4. Thermal distribution cases for randomly distributed thermals.

\begin{tabular}{ccccc}
\hline \hline $\begin{array}{c}\text { Set } \\
\text { index }\end{array}$ & $\begin{array}{c}\text { Case } \\
\text { index }\end{array}$ & $\begin{array}{c}\text { Start } x \\
(\mathrm{~km})\end{array}$ & $\begin{array}{c}\text { Start } y \\
(\mathrm{~km})\end{array}$ & $\begin{array}{c}\text { Thermal } \\
\text { coverage } \\
(\%)\end{array}$ \\
\hline C & 10 & 13.040 & 69.993 & 36.98 \\
C & 11 & 8.722 & 13.230 & 45.51 \\
C & 12 & 9.370 & 33.534 & 34.57 \\
C & 13 & 10.485 & 86.348 & 36.70 \\
C & 14 & 19.533 & 57.023 & 25.34 \\
D & 15 & 5.534 & 57.670 & 35.24 \\
D & 16 & 10.690 & 75.454 & 41.56 \\
D & 17 & 11.664 & 86.362 & 32.95 \\
D & 18 & 18.246 & 23.703 & 34.08 \\
D & 19 & 13.242 & 8.069 & 34.87 \\
E & 20 & 11.091 & 58.334 & 29.29 \\
E & 21 & 15.371 & 62.630 & 41.14 \\
E & 22 & 7.016 & 81.647 & 32.57 \\
E & 23 & 11.779 & 32.161 & 37.42 \\
E & 24 & 6.491 & 10.903 & 34.88 \\
\hline
\end{tabular}

pattern could be flown in 24-26 min, which we felt was still sufficiently short to yield a quasi-stationary, early afternoon BL during the three A/D pairs. Figure 10 shows the total flight track, of which only the vertical
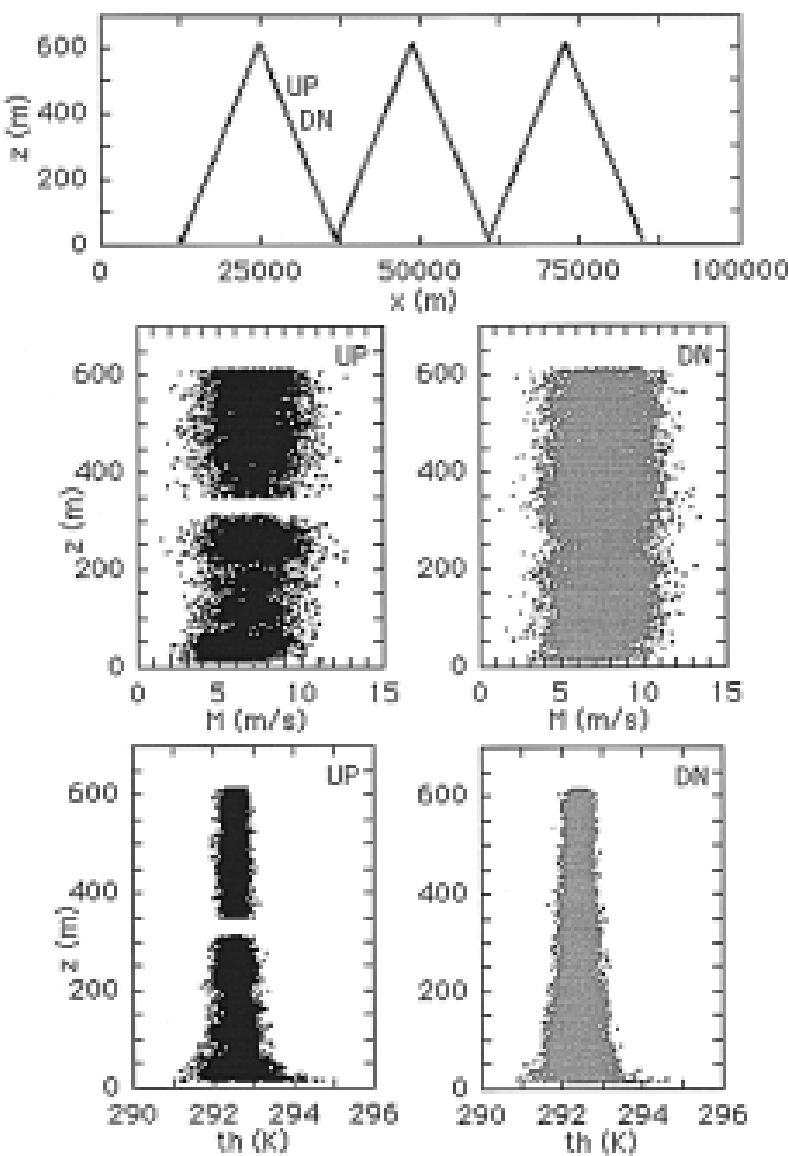

FIG. 4. Same as Fig. 1, but for the randomly distributed thermals of trial C10. The total number of synthetic data points is 36000 .
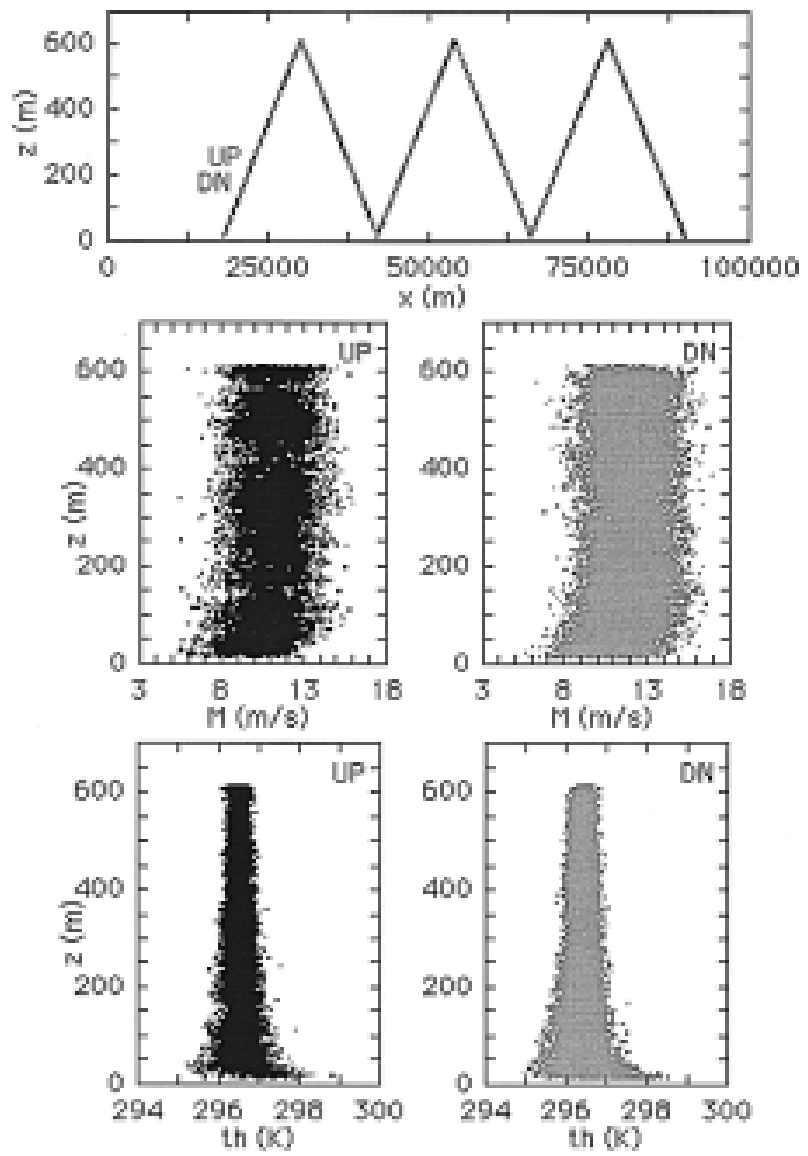

FIG. 5. Same as Fig. 4, but for trial D18.

zigzag portions were associated with this RxL subexperiment.

There were 12 successful research flights, each of about 4.5-h duration for all subexperiments (see Berg et al. 1997 for the airborne scientist flight logs). In every flight two sets of zigzag measurements of horizontal wind and temperature were collected. After quality controlling the data, there were only 10 flights that were adequate for analysis. As for the synthetic data, mean wind and potential temperature were calculated by averaging wind and temperature within nonoverlapping bins of 2-m depth and assigned to altitudes at the bin centers. The altitude AGL was measured by two radar altimeters. The actual lowest altitudes of the slant A/D legs varied from 6 to $28 \mathrm{~m}$ AGL, depending on flight obstructions near the surface.

\section{c. Field results}

A subset of results for Lamont, Winfield, and Meeker is shown in Figs. 11-13. The BLX96 mean wind data exhibit more scatter than temperature over the whole vertical domain (in the SL, the RxL, and the UL). For UL winds less than $3 \mathrm{~m} \mathrm{~s}^{-1}$, the data do not show consistent profile forms. For faster UL winds, the observed 

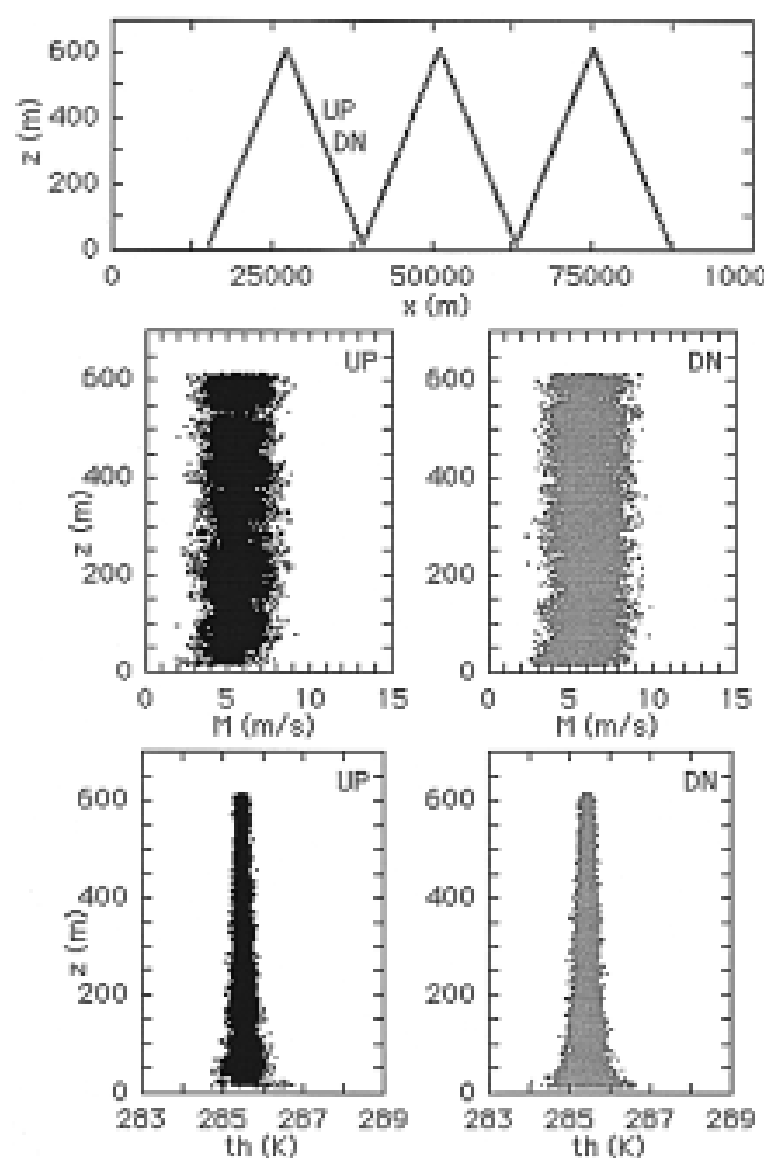

FIG. 6. Same as Fig. 4, but for trial E21.

profiles showed the expected patterns of slower winds near the surface that smoothly increase until becoming tangent to uniform winds in the mid-ML. For temperature profiles, the data exhibited an RxL merging into a UL and was quite well defined within the UL. Comparing plotted data from all sites, the Lamont track, which was the flattest and smoothest, had slightly less scatter.

Based on our analysis of the synthetic data, we ex-

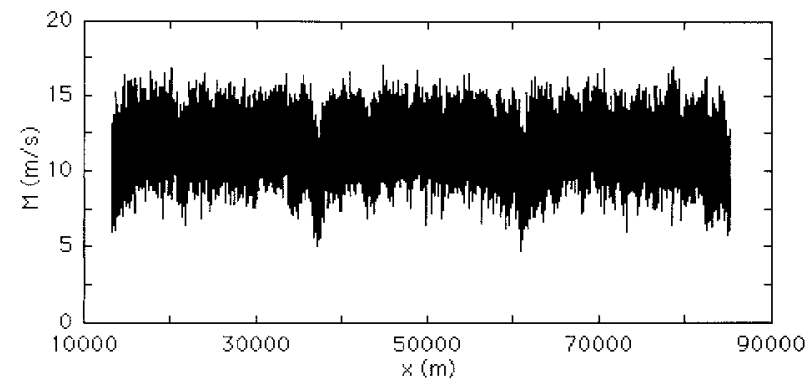

FIG. 7. An example of the time series of synthetic data as would have been measured at $50 \mathrm{~Hz}$ by a virtual aircraft flying a vertical zigzag flight through randomly distributed thermals at horizontal speed $100 \mathrm{~m} \mathrm{~s}^{-1}$, for trial D19.
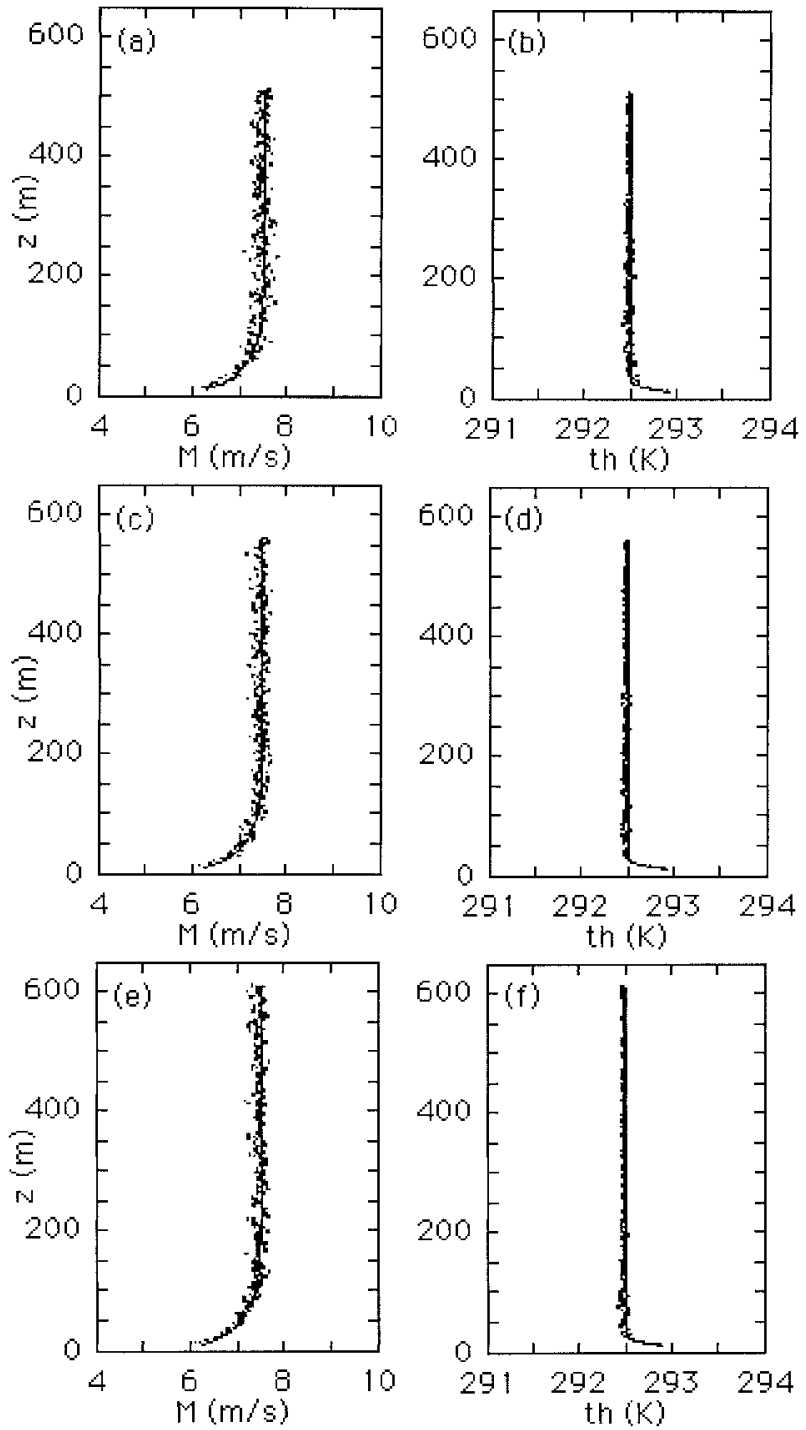

FIG. 8. Wind (M) and potential temperature (th) profiles computed after sorting the raw data into height bins of 2-m depth, and averaging to yield the data points plotted here. Solid lines are the best-fit nonlinear regression of the radix layer curves 1 and 2 to the data points. These best-fit lines are so close to the desired (input) profiles that they cannot be distinguished. (a) and (b) Trial A01, (c) and (d) A04, and (e) and (f) A05.

pected the BLX96 vertical zigzag flights to reach sufficiently low altitude to yield a robust sample of the profile curvature near the bottom of RxL. However, actual terrain conditions and obstructions near the surface precluded measurement at sufficiently low altitude, for safety reasons. Occasionally at the bottom of some A/D flights we reached altitudes lower than $10 \mathrm{~m}$, but most flights were unable to get that low. Measured RxL characteristics for BLX96 will be discussed in a separate paper.

Other types of difficulties were found in the BLX96 data. For some flights we found that mean values of 

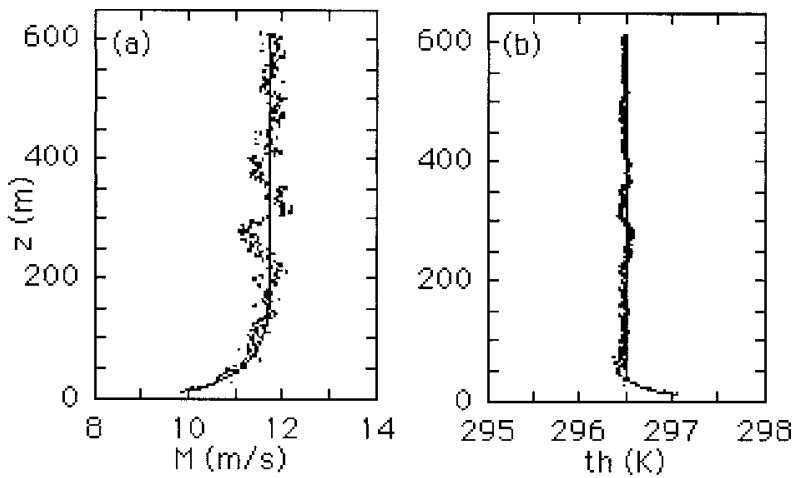

TABLE 5. Best fit radix layer parameters to the synthetic data, for evenly distributed thermals. The rows labeled "input" are the desired parameters for each meteorological set. If there were no sampling errors, and if the data analysis algorithms contain no errors, then the parameters analyzed from each of the trials should be identical to the input parameter values for that same meteorological set. The spread of trial values about the desired input value indicates the experimental error that could be expected if this synthetic experiment were repeated in the real atmosphere, except as recommended in the conclusions section.

\begin{tabular}{cccccc}
\hline \hline Trial & $\begin{array}{c}z_{r m} \\
(\mathrm{~m})\end{array}$ & $\begin{array}{c}z_{r t} \\
(\mathrm{~m})\end{array}$ & $\begin{array}{c}M_{\mathrm{UL}} \\
\left(\mathrm{m} \mathrm{s}^{-1}\right)\end{array}$ & $\begin{array}{c}\theta_{\mathrm{UL}} \\
(\mathrm{K})\end{array}$ & $\begin{array}{c}\theta_{0} \\
(\mathrm{~K})\end{array}$ \\
\hline A input & 185.0 & 32.0 & 7.50 & 292.50 & 302.50 \\
A01 & 178.0 & 32.7 & 7.51 & 292.50 & 302.50 \\
A02 & 188.0 & 32.4 & 7.50 & 292.50 & 302.50 \\
A03 & 176.0 & 32.5 & 7.49 & 292.50 & 302.50 \\
A04 & 176.1 & 32.6 & 7.49 & 292.50 & 302.50 \\
A05 & 193.0 & 31.8 & 7.51 & 292.50 & 302.50 \\
A06 & 193.0 & 31.5 & 7.51 & 292.50 & 302.50 \\
B input & 130.0 & 25.0 & 6.00 & 285.50 & 290.50 \\
B01 & 135.0 & 23.9 & 6.00 & 285.50 & 290.50 \\
B02 & 123.5 & 24.1 & 5.99 & 285.50 & 290.50 \\
B03 & 122.8 & 23.8 & 6.00 & 285.50 & 290.50 \\
B04 & 126.2 & 25.8 & 6.00 & 285.50 & 290.50 \\
B05 & 139.3 & 25.0 & 6.01 & 285.50 & 290.50 \\
B06 & 128.8 & 23.7 & 6.00 & 285.50 & 290.50 \\
\hline
\end{tabular}

the conditions were all ideal, including factors such as a flat homogeneous surface; conservation of mass, heat, and momentum within the horizontal and vertical flight distances; stationarity during any one flight leg; and no acceleration or deceleration in virtual aircraft's speed, pitch, and roll. That the real data did not exhibit these idealized traits suggests that more sophisticated synthetic experiments could be developed in the future.

\section{d. Discussion}

In the real atmosphere, thermals are distributed somewhat randomly, their diameters vary from several hun-

FIG. 9. Same as Fig. 8, except for the randomly distributed thermals. The increased scatter in these data is more representative of the scatter expected from measurements in the real atmosphere. (a) and (b) Trial D10, (c) and (d) D12, and (e) and (f) D14.

wind in the RxL were faster than in the UL, due to either baroclinicity or sampling error. Analogous errors of potential temperature being cooler in the RxL than in the UL were also found. This could have been caused by the fact that the lowest point in the A/D legs were, by chance, over a surface feature that did not have a land use near the median of land uses for that track.

Compared to mean wind and potential temperature profiles from the synthetic data, the actual values of mean wind have more scatter, while those for temperature have roughly equivalent scatter. Nonetheless, the actual values were sufficiently robust to allow a good analysis, considering that some of the real conditions were far from perfect compared to those of the synthetic cases. As explained previously, in the synthetic cases

TABLE 6. Same as Table 5, but for randomly distributed thermals.

\begin{tabular}{cccccc}
\hline \hline Trial & $\begin{array}{c}z_{r m} \\
(\mathrm{~m})\end{array}$ & $\begin{array}{c}z_{r t} \\
(\mathrm{~m})\end{array}$ & $\begin{array}{c}M_{\mathrm{UL}} \\
\left(\mathrm{m} \mathrm{s}^{-1}\right)\end{array}$ & $\begin{array}{c}\theta_{\mathrm{UL}} \\
(\mathrm{K})\end{array}$ & $\begin{array}{c}\theta_{0} \\
(\mathrm{~K})\end{array}$ \\
\hline C input & 200.0 & 34.0 & 7.50 & 292.50 & 302.50 \\
C10 & 214.9 & 38.1 & 7.50 & 292.51 & 302.50 \\
C11 & 260.2 & 41.9 & 7.48 & 292.51 & 302.50 \\
C12 & 226.9 & 33.6 & 7.51 & 292.51 & 302.50 \\
C13 & 223.2 & 39.9 & 7.50 & 292.51 & 302.50 \\
C14 & 201.6 & 37.5 & 7.55 & 292.49 & 302.50 \\
D input & 245.0 & 50.0 & 11.80 & 296.50 & 304.50 \\
D15 & 177.5 & 47.6 & 11.73 & 296.50 & 304.50 \\
D16 & 214.5 & 54.7 & 11.70 & 296.51 & 304.50 \\
D-17 & 279.2 & 54.9 & 11.83 & 296.50 & 304.50 \\
D-18 & 222.7 & 52.2 & 11.74 & 296.50 & 304.50 \\
D-19 & 314.4 & 62.6 & 11.84 & 296.50 & 304.50 \\
E input & 150.0 & 28.0 & 6.00 & 285.50 & 290.50 \\
E20 & 149.6 & 29.1 & 6.02 & 285.49 & 290.50 \\
E21 & 115.6 & 22.5 & 5.95 & 285.51 & 290.50 \\
E22 & 113.4 & 25.7 & 5.98 & 285.50 & 290.50 \\
E23 & 155.2 & 26.8 & 5.98 & 285.50 & 290.50 \\
E24 & 124.5 & 25.9 & 5.98 & 285.50 & 290.50 \\
\hline
\end{tabular}



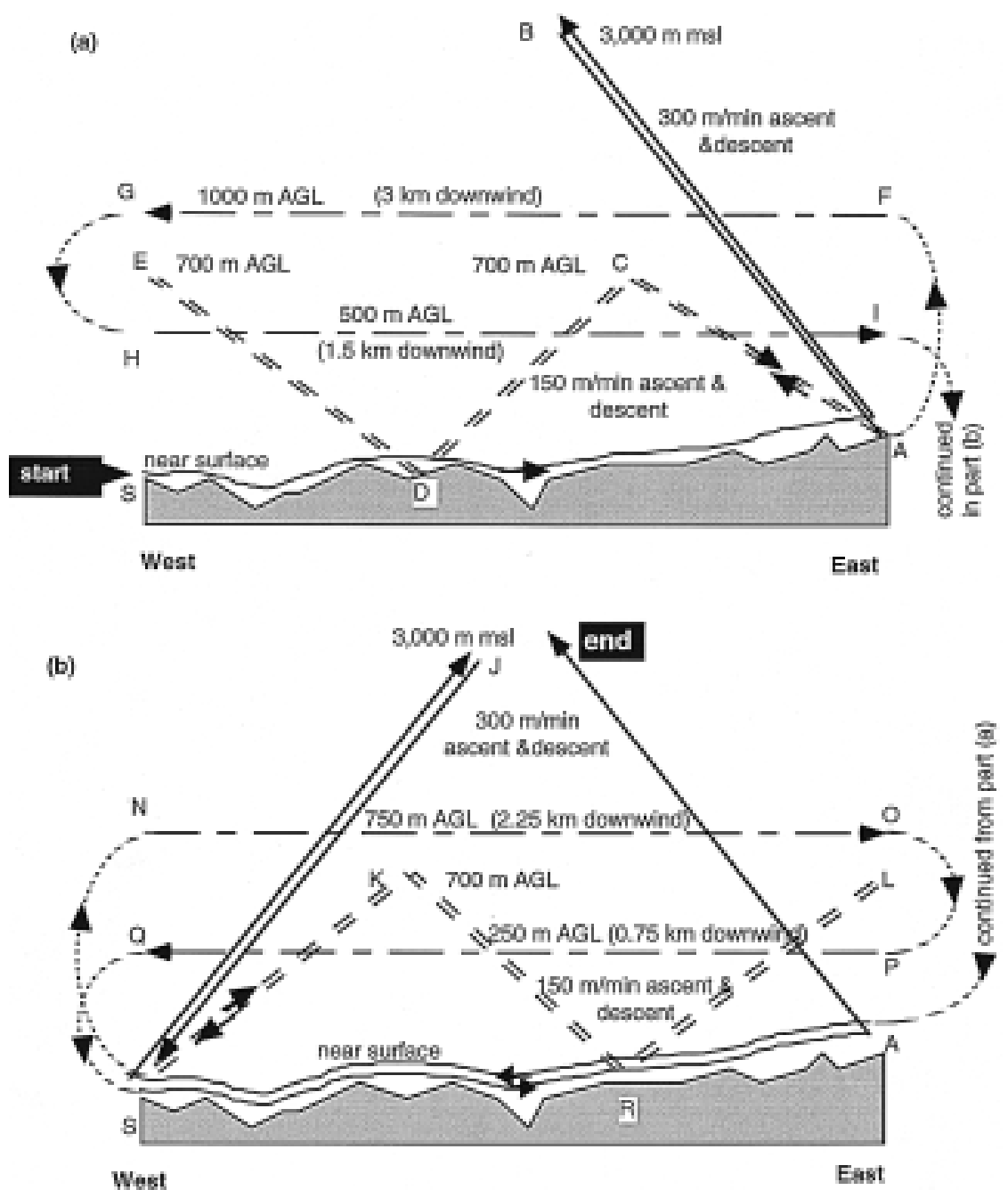

FIG. 10. (a) Sketch of typical east-west flight pattern during the BLX96 field experiment in Oklahoma and Kansas. Solid lines indicate measurement of ML scaling variables, and the dashed lines indicated the vertical zigzag pattern designed for measurement of the radix layer. The longshort dash line was for other subexperiments, and dotted lines represent ascent/descent turns made outside the measurement domain. (b) A continuation of (a), which together yield two full radix layer patterns flown during each aircraft flight. Letters index key points during the flight; for example, a zigzag pattern that travels through points ACDEDCA would be indexed using their starting and ending points as AA. During each flight the key points were encountered in the following order: S, A, B, A, C, D, E, D, C, A, F, G, H, I, A, S, J, S, K, R, L, R, K, S, N, $\mathrm{O}, \mathrm{P}, \mathrm{Q}, \mathrm{S}, \mathrm{A}$, end.

dreds of meters to order 1 or $2 \mathrm{~km}$, and they are not uniform in diameter from bottom to top. For randomly distributed, variable diameter, nonuniform thermals, it was possible that conservation of mass, heat, and momentum was not satisfied within our finite-length flight legs. At the time of the experiment it was also possible that the thermal coverages were less than those assumed; therefore our modified flight pattern might not have been long enough to sample data representatively. Consequently, when we calculated averaged mean values in every bin, the results still contained some scatter, because of the imbalance between the thermal up- and downdrafts and background air.
Also, while the actual flight conditions for any one flight leg appeared quasi stationary based on visual examination of the real time series, the amount of nonstationarity remaining was nonetheless important compared to the stationary synthetic data. However, it should be possible to simulate nonstationary MLs by applying a time-varying $z_{i}$ in (9)-(11) before sampling with the virtual aircraft, something worth considering by future investigators.

For the real flights, it was difficult to maintain constant speed, pitch, and roll, especially in the zigzag flight or when avoiding obstacles such as hills, power transmission poles, radio towers, or oil derricks. Though 

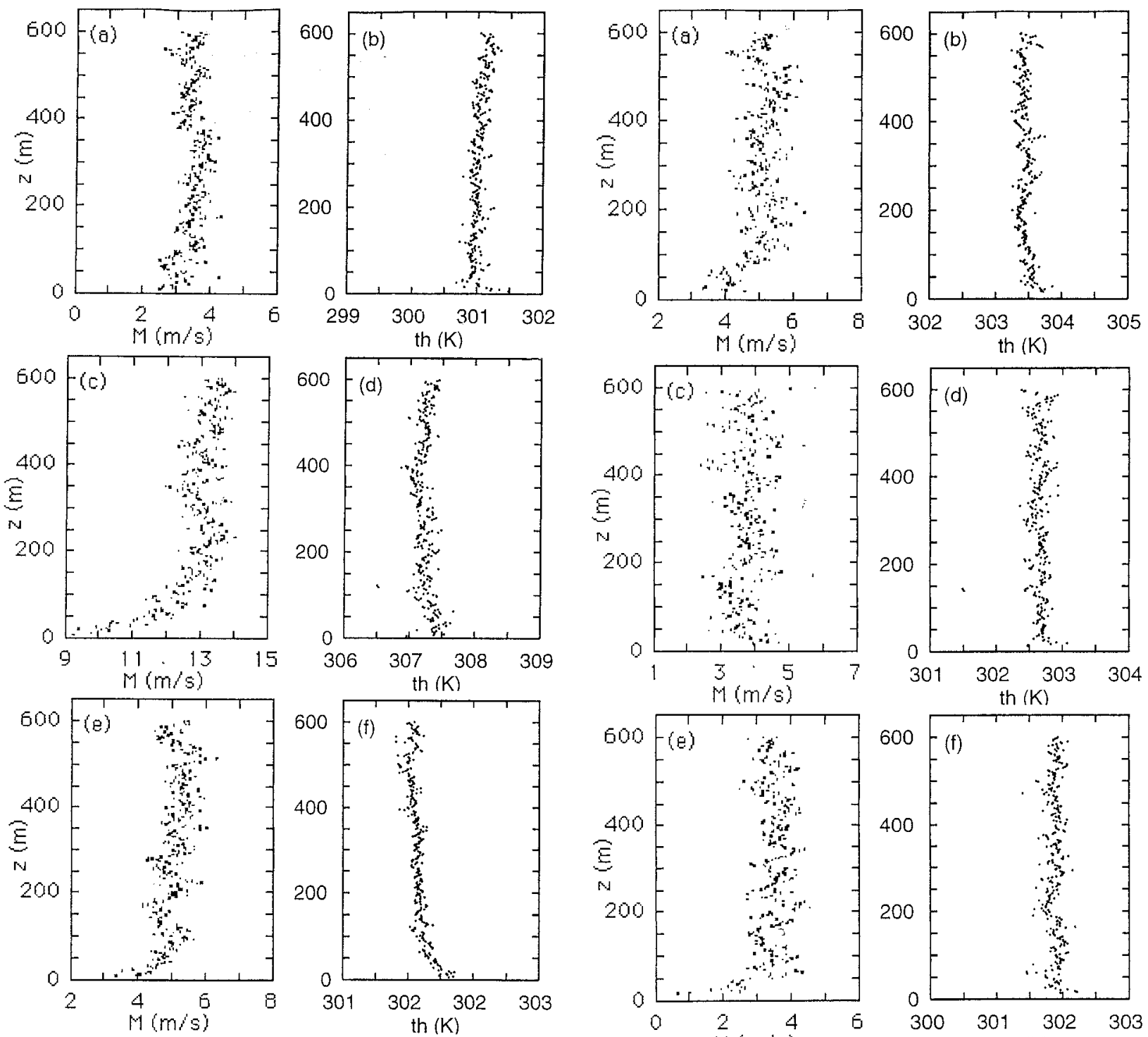

FIG. 11. Same as Fig. 9, but using real wind speed (M) and potential temperature (th) data from the BLX 96 field program from flights over the Lamont site. (a) and (b) From 27 July 1996 track SS, (c) and (d) 4 Aug 1996 track AA, and (e) and (f) 13 Aug 1996 track SS.

most of the intervals of acceleration, deceleration, and maneuvers have been excluded from our data during quality control, some errors cannot be excluded totally. Sometimes the aircraft temporarily followed locally sloping terrain, as it descended and ascended in valleys or elevated areas. In this kind of flight, though the aircraft was ascending or descending, the radar altitude measurements were not parallel to pressure heights, thereby possibly causing more scatter in the averaged values.

Comparing the real observations of Figs. 11-13 with the synthetic observations of Fig. 9, the real data exhibit roughly twice as much spread as the synthetic. The main reason is that the empirical relationships in the literature
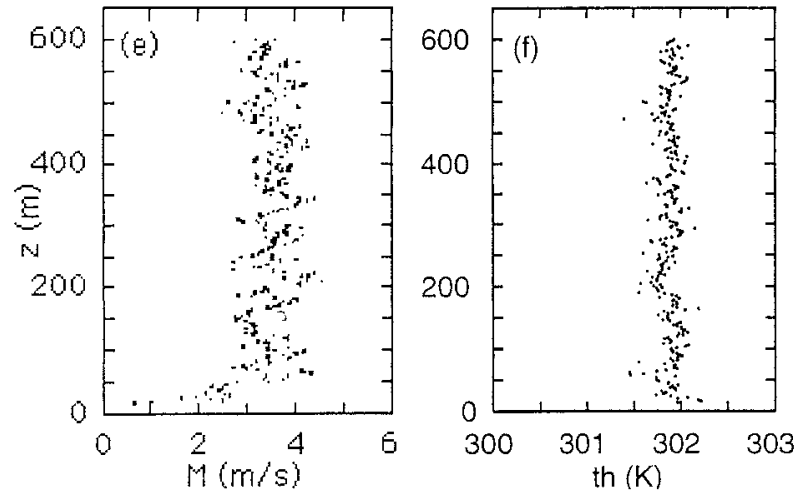

Fig. 12. Same as Fig. 11 but for the Winfield site. (a) and (b) From 15 July 1996 track SS, (c) and (d) 25 July 1996 track AA, and (e) and (f) 31 July 1996 track AA.

that were used to generate the synthetic data were based on observations either at a fixed point (in the case of tower data), or over a surface that was much more horizontally homogeneous than was actually observed during BLX96. Because the BLX96 field experiment was specifically designed to gather data over heterogeneous surfaces, we should have anticipated larger standard deviations of wind and potential temperature associated both with the random small-medium eddies and with the larger coherent thermal structures.

\section{Conclusions and recommendations}

We flew a virtual aircraft through synthetic data to help design a boundary layer field campaign and to help 

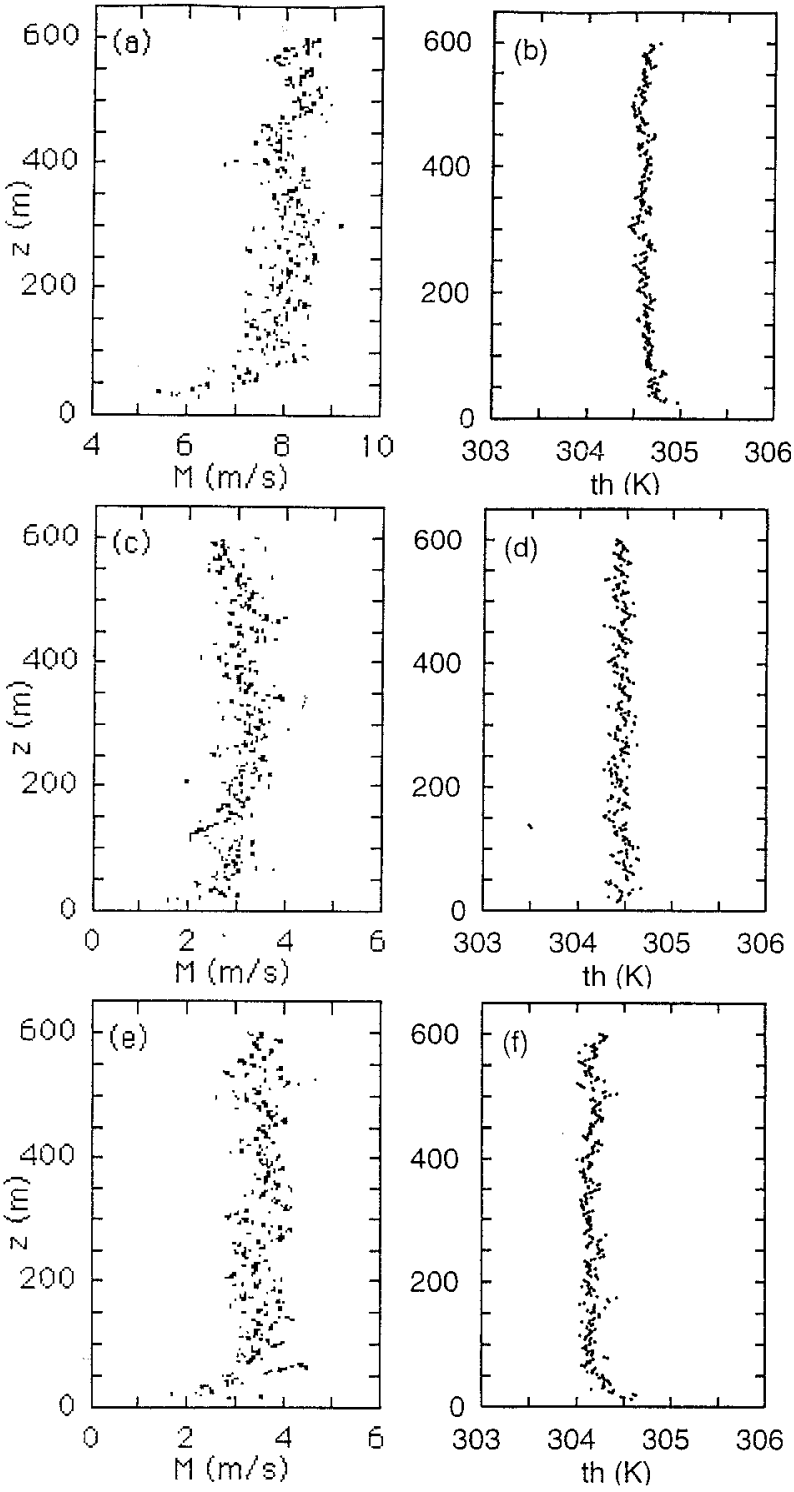

FIG. 13. Same as Fig. 11, but for the Meeker site. (a) and (b) From 16 July 1996 track SS, (c) and (d) 28 July 1996 track SS, and (e) and (f) 2 Aug 1996 track SS.

test our data analysis algorithms. Our first synthetic experiments used evenly spaced thermals and did not exhibit the complexity and sampling error that we anticipated in real life. A second set of synthetic experiments included more realistic quasi-random spacing and diameters of thermals, which we used to design the flight patterns of the real field program. Perhaps a lognormal distribution would have been an even better representation of thermal characteristics, and we thus recommend its use in future simulations by other investigators.

When the real field program BLX96 was flown over Oklahoma and Kansas, there were many additional complications beyond those anticipated in our simulations, including a heterogeneous surface and a nonstationary boundary layer. As such complications would probably differ from field experiment to field experiment, it is difficult to make specific recommendations on how to produce more realistic synthetic experiments. In fact, no matter what level of sophistication is included in the generation of synthetic data, there will always be additional unanticipated complications in real life.

Instead, we recommend that a common engineering approach be used. We observe that the published turbulence standard deviations of (7) and (8) and the maximum thermal updraft and downdraft perturbations of (3)-(6) are too small by a factor of roughly 2 . If investigators wish to simulate a heterogeneous land use similar to that under our flight tracks in Oklahoma and Kansas, then we recommend that the literature values of standard deviation and the thermal perturbations be multiplied by a factor of 2 before being used to generate synthetic data.

If investigators want a conservative estimate that will likely work for a wider variety of heterogeneous land use, then we recommend that a scaling factor of 3 or 4 be used instead. This should increase the sampling error within the synthetic time series to hopefully be slightly worse than real life. Data analysis algorithms that prove successful with these degraded data would have a greater chance of succeeding with actual data.

From BLX96 we did gain new insight into the workings of the radix layer. These new results will soon be published. So in that sense, while our simulation was far from perfect, it successfully served its purpose by allowing us to design a useful flight track for real life.

In a broader sense perhaps there is more that can be learned, as suggested by one of the paper's referees: "The authors eventually found that nature tends to confound the simulator of observational data. While the engineering approach . . . is a practical method for solving a particular problem, I would urge the authors and anyone else ... to consider the inherent value of the process of doing the observation simulations. There may be useful insights gained by comparing simulated observation behavior with that obtained from real data. Ideally, the process of observation simulation should evolve with our improved understanding of atmospheric processes."

Acknowledgments. This research was funded by the U.S. National Science Foundation (NSF) under Grant ATM-9411467. The University of Wyoming King Air aircraft is also sponsored by NSF. The Canadian Natural Science and Engineering Research Council (NSERC) and the Environment Canada Atmospheric Environment Service (AES) also provided grant support. The U.S. Department of Energy is gratefully acknowledged for their Grant DE-FG02-92ER61361, as well as for their data and field support at the Southern Great Plains Atmospheric Radiation Measurement (ARM) program. Josh Hacker provided excellent daily forecasts that were used for flight planning and served as an airborne sci- 
entist, and Larry Berg also served as one of the airborne scientists.

\section{REFERENCES}

Atlas, R., E. Kalnay, W. E. Baker, J. Susskind, D. Reuter, and M. Halem, 1985: Simulation studies of the impact of future observing system on weather prediction. Preprints, Seventh Conf. on Numerical Weather Prediction, Montreal, PQ, Canada, Amer. Meteor. Soc., 145-151.

Bell, T. L., 1987: A space-time stochastic model of rain fall for satellite remote sensing studies. J. Geophys. Res., 92, 96319643.

Berg, L. K., R. B. Stull, E. Santoso, and J. P. Hacker, 1997: Boundary Layer Experiment-1996 (BLX96) airborne scientist flight log. Boundary Layer Research Team Tech. Note BLRT-97-1, 116 pp. [Available from R. Stull, Atmospheric Science Programme, Department of Geography, University of British Columbia, 1984 West Mall, Vancouver, BC V6T IZ2, Canada.]

Caughey, S. J., and S. G. Palmer, 1979: Some aspects of turbulent structure through the depth of the convective boundary layer Quart. J. Roy. Meteor. Soc., 105, 811-827.

Godowitch, J. M., 1986: Characteristics of vertical turbulence velocity in the urban convective boundary layer. Bound.-Layer Meteor., 35, 387-407.

Green, R. N., 1983: Accuracy and resolution of earth radiation budget estimates. J. Atmos. Sci., 40, 977-985.

Greenhut, G. K., and S. J. S. Khalsa, 1982: Updraft and downdraft events in the atmospheric boundary layer over the equatorial Pacific Ocean. J. Atmos. Sci., 39, 1803-1818.

$\longrightarrow$, and 1987: Convective elements in the marine atmospheric boundary layer. Part I: Conditional sampling statistics. J. Climate Appl. Meteor., 26, 813-822.

Hedin, A. E., 1991: Extension of the MSIS thermospheric model into the middle and lower atmosphere. J. Geophys. Res., 96, 11591172 .

Izumi, Y., and J. S. Caughey, 1976: Minnesota 1973 Atmospheric Boundary Layer Experiment data report. Tech. Rep. AFCRLTR-76-0038, 28 pp. [Available from R. Stull, Atmospheric Science Programme, Department of Geography, University of British Columbia, 1984 West Mall, Vancouver, BC V6T IZ2, Canada.]

Khalsa, S. J. S., and G. K. Greenhut, 1985: Conditional sampling of updrafts and downdrafts in the marine atmospheric boundary layer. J. Atmos. Sci., 42, 2550-2562.

_ and - 1987: Convective elements in the marine atmospheric boundary layer. Part II: Entrainment in the capping inversion. J. Climate Appl. Meteor., 26, 824-836.

Lenschow, D., X. S. Li, C. J. Zhu, and B. B. Stankov, 1988a: The stably stratified boundary layer over the Great Plains: 1 . Mean and turbulence structure. Bound.-Layer Meteor., 42, 95-121.
S. F. Zhang, and B. B. Stankov, 1988b: The stably stratified boundary layer over the Great Plains: 2. Horizontal variations and structure. Bound.-Layer Meteor., 42, 95-121.

Liou, K.-N., and S.-C. Ou, 1979: Infrared radiative transfer in finite cloud layers. J. Atmos. Sci., 36, 1984-1996.

Meneghini, R., K. Nakamura, C. W. Ulbrich, D. Atlas, T. D. Clem, and S. R. Kostic, 1986: Comparison of methods using data from an airborne dual-wavelength radar. Preprints, 23 d Conf. on Radar Meteorology and Conf. on Cloud Physics, Snowmass, CO, Amer. Meteor. Soc., 100-103.

Panofsky, H. A., H. Tennekes, D. H. Lenschow, and J. C. Wyngaard, 1977: The characteristics of turbulent velocity components in the surface layer under convective conditions. Bound.-Layer Meteor., 11, 355-361.

Press, W. H., B. P. Flannery, S. A. Teukolsky, and W. T. Vetterling, 1992: Numerical Recipes in FORTRAN: The Art of Scientific Computing. 2d ed. Cambridge University Press, 963 pp.

Santoso, E., 1993: A wind-profile relationship for the unstable surface layer/mixed-layer system. M.S. thesis, Department of Atmospheric and Oceanic Sciences, University of Wisconsin-Madison, $59 \mathrm{pp}$.

_ , and R. Stull, 1998: Wind and temperature profiles in the radix layer, the bottom fifth of the convective boundary layer. J. Appl. Meteor., 37, 545-558.

Smedman-Högström, A. S., and U. Högström, 1978: A practical method for determining wind frequency distributions for the lowest $200 \mathrm{~m}$ from routine meteorological data. J. Appl. Meteor., 17, 942-954.

Sorbjan, Z., 1986: On similarity in the atmospheric boundary layer. Bound.-Layer Meteor., 34, 377-397.

Stull, R., 1988: An Introduction to Boundary Layer Meteorology. Kluwer Academic, 818 pp.

, 1990: Similarity relationship handbook. Boundary Layer Research Team Tech. Note BLRT-90-1, 51 pp. [Available from R. Stull, Atmospheric Science Programme, Department of Geography, University of British Columbia, 1984 West Mall, Vancouver, BC V6T 1Z2, Canada.]

1996: Reply. J. Atmos. Sci., 54, 579.

, E. Santoso, L. Berg, and J. Hacker, 1997: Boundary Layer Experiment 1996 (BLX96). Bull. Amer. Meteor. Soc., 78, 11491158.

Wieringa, J., 1980: Representativeness of wind observations at airports. Bull. Amer. Meteor. Soc., 61, 962-971.

, 1986: Roughness-dependent geographical interpolation of surface wind speed averages. Quart. J. Roy. Meteor. Soc., 112, 867889.

Young, G. S., 1988a: Turbulence structure of the convective boundary layer. Part I: Variability of normalized turbulent statistics. $J$. Atmos. Sci., 45, 719-726.

_ 1988b: Turbulence structure of the convective boundary layer. Part II: Phoenix 78 aircraft observations of the thermals and their environment. J. Atmos. Sci., 45, 727-735. 